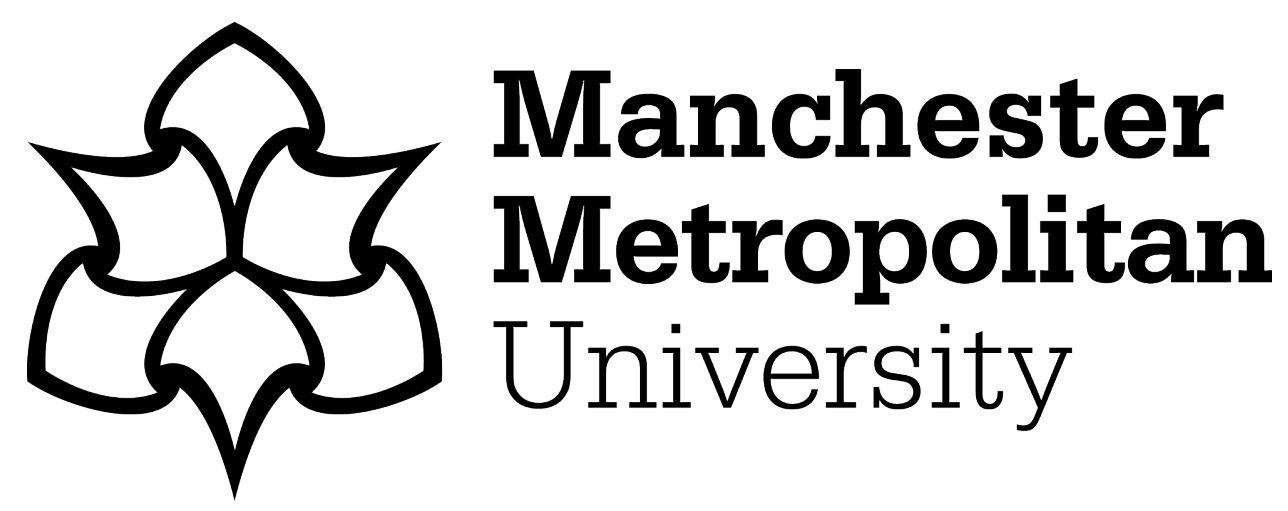

Del Teso Sánchez, K, Allen, NS, Liauw, Christopher and Edge, Michelle (2014) Effect of polymerization catalyst technology on the melt processing stability of polyethylenes, Part 3: Additives blends performance. Journal of Vinyl and Additive Technology, 22 (2). pp. 117-127. ISSN 1083-5601

Downloaded from: https://e-space.mmu.ac.uk/620983/

Publisher: Wiley

DOI: https://doi.org/10.1002/vnl.21421

Please cite the published version 


\section{Effect of Polymerization Catalyst Technology on the Melt Processing Stability of Polyethylenes. Part 3: Additives blends performance.}

Karmele del Teso Sánchez ${ }^{\mathrm{a} *}$, Norman S. Allen ${ }^{\mathrm{b}}$, Christopher M. Liauw ${ }^{\mathrm{b}}$, Michelle Edge ${ }^{\mathrm{b}}$

${ }^{a}$ Mondragon Unibertsitatea, Mondragon Goi Eskola Politeknikoa, Loramendi 4, 20500 ArrasateMondragon, España.

${ }^{\mathrm{b}}$ School of Biology, Chemistry and Health Science, Manchester Metropolitan University, Chester Street, Manchester M1 5GD, United Kingdom.

* Corresponding author. Tel.: + 34943794700 ext. 6442

E-mail address: kdelteso@mondragon.edu

Keywords: Degradation, Polyethylene, Additive blends, Color, Melt Flow Index. 


\begin{abstract}
This paper considers the interaction between additives that occur during the stabilization process. The simultaneous effects of the additives and associated interactions on melt processing stability and processing discoloration were of particular interest. Melt stability is an important factor to consider since physical changes in the processed polymer can occur during the compounding and fabrication steps. Furthermore, discoloration is one of the most important problems affecting commercial polymers. Most discoloration manifests itself as yellowing, especially in the case of polyolefins. Whilst yellowing can be often associated with degradation processes caused by various agents such as light or heat, this is not always the case; yellowing can be also due to the interaction of additives in the stabilizer packages.

Blends of primary antioxidants, secondary antioxidants and hindered amine light stabilisers have been studied with the intention of further improving stabilization performance together with cost reduction of the stabilized polymer. Although synergism between antioxidants and a stabilizer is fairly common, antagonism was also observed in terms of melt flow protection and in color stability in some of the AOs tested.

The effects of a range of thermal and light stabilizers on the melt stability (investigated via multiple pass extrusion) and color stability of three different polyethylenes (PEs) were examined. The PEs varied in terms of the catalyst system used to synthesize the polymers and included an HDPE produced by using a chromium-based Phillips catalyst and two LLDPEs produced via chromium-based metallocene and titanium based Ziegler-Natta catalysts. The apparent lack of influence of polymerization catalyst system on the mode of stabilizer interaction should lead to the reassessment of stabilizer formulation strategies in relation to PE type/catalyst system and associated commercial/economic considerations.
\end{abstract}




\section{Introduction}

Traditional stabilizer systems are based usually on two or more antioxidants e.g. a combination of a primary phenolic antioxidant ( $\mathrm{AO}$ and a phosphorus-based melt processing stabilizer (also known as a secondary AO). The former improves melt processing stability by acting as a chain breaking donor and a scavenger of free radicals, whilst the latter operates as a hydroperoxide decomposer during melt processing [1]. Combinations of these types of stabilizer are often synergistic, in such cases the effect of the combination is greater than the sum of each individual contribution at a given loading [2]. Antagonism is also possible but is not so frequently encountered $[3,4]$.

The stabilizer package investigated in this study represents current formulation practice and was composed of the following: primary phenolic AO, organo phosphite or thioether (secondary AO / peroxide decomposer), hindered amine light stabilizer (HALS) (or a hydroxylamine), and acid scavenger.

Due to the diversity of the nature of the additives present in such stabilizer packages, interactions between additives are likely to occur. These potentially complex interactions could have detrimental effects in terms of melt processing stability and color development during processing. The following additive combinations were investigated in order to further investigate these effects:

Phenolic AO + Phosphite $\rightarrow$ Improved melt flow retention and better color.

Phenolic AO + Thioether $\rightarrow$ Improved long term heat ageing (LTHA) performance.

Phenolic AO + Hydroxylamine $\rightarrow$ New blends, double functionality of hydroxylamine.

Phenolic AO + HALS $\rightarrow$ Improve UV protection.

The use of more than one additive for the stabilization of polyolefins is common for various reasons: (a) The article may be exposed to more than one source of incident radiation during its end-use. (b) One the components of a formulation may be cheaper and can thus be used in greater quantities, and (c) A formulation may exhibit the phenomenon of synergism which results in a higher overall efficiency [2].

Interactions and possible synergism between different AOs were evaluated according to their efficiency as an antioxidant in PE. The aim was to evaluate the performance of the additives when used alone or in 
blends. If synergism is observed, the goal has been to determine the best combination ratio of additives to protect the polymer during processing and end-use, with optimum cost-performance ratio.

The results were presented and analyzed in terms of melt flow rate (MFR) and yellowness index (YI) values. From previous work and other published studies, it is well known [5] that phenolic AO are likely to give rise to yellowing due to the formation of highly chromophoric transformation products. Replacing the phenolic AO with phosphites, HALS or hydroxylamine has been shown to have a positive effect on suppression of yellowing. In this study a similar behavior will be investigated. The results were compared with the performance of the additives when used in isolation [6,7]. 


\section{Experimental}

\section{Materials}

The polyethylene types investigated (Table 1) were commercially produced via three different catalyst technologies, and the eight stabilizers selected are described in Tables 2 to 4; these stabilizers were selected with the intention of representing the current state of the art in stabilization technology whilst also bearing in mind the their differing roles and activities. For comparative use, all the products were tested individually at a load level of $250 \mathrm{ppm}$. All the formulations also contained $500 \mathrm{ppm}$ zinc stearate $(\mathrm{ZnSt})$ as an acid scavenger.

\section{Multi-pass extrusion and film preparation}

Multi-pass extrusion may be considered a type of accelerated ageing for simulating commercial processing conditions [8,9]. The method involves repeatedly passing the polymer through an extruder and then collecting the samples after each pass. In the extruder the polymer is melted by conduction from the barrel wall and by shear, therefore in the presence of dissolved oxygen, oxidative and mechano-oxidative degradation can occur [10]. Each polyethylene (PE) was subjected to six extrusion passes (numbered 0-5) and samples of each pass were collected for further analysis. The extruder used was a Brabender single screw extruder $(\mathrm{D}=19 \mathrm{~mm}, \mathrm{~L} / \mathrm{D}=0.44$ and compression ratio of 4$)$ attachment for a Brabender PL2000 dynanometer drive unit. Processing began with $1.2 \mathrm{~kg}$ of polymer for pass 0 . After passes $0,1,3$ and 5 , $190 \mathrm{~g}$ of extrudate was collected. The temperature profile is described in Table 5.

Films (ca. $100 \mu \mathrm{m}$ thick) were produced by compression molding at $190{ }^{\circ} \mathrm{C}$ between polished stainless steel plates. About 10 granules of PE were placed between the pre-heated plates. The platens were held in contact with (but not compressing) the granules for 1 minute to ensure uniform heating. The clamping line pressure was then increased to 50 Bar and held for 1 minute and then increased to 150 Bar and held for a further minute before transferring the mould to a water cooled press. Samples of film $(100 \mu \mathrm{m} \pm 10 \mu \mathrm{m})$ were selected using a micrometer.

\section{Characterization}

Melt flow rate (MFR): The MFR of material collected after extruder passes 0, 1, 3 and 5 was determined using semi-automatic Ceast 16412 / 16861 MFR instruments, with $10 \mathrm{~kg}$ and $21.6 \mathrm{~kg}$ loads. Set 
temperature was at $190^{\circ} \mathrm{C}$ [11]. A decrease in MFR indicates chain extension/crosslinking and a increase in MFR indicates chain scission. Therefore changes in MFR can provide insight in to the overall balance of these reactions.

Yellowness index (YI) determination: Discoloration is one of the most important problems affecting commercial polymers $[12,13]$. YI is often used to measure color development in polymers and is obtained from the values of $a, b$ and $L$ coordinates of the three-dimensional CIE (International Commission on Illumination) $L^{*} a^{*} b^{*}$ model that can be used to represent any color, $L^{*}$ represents lightness, $a^{*}$ approximates redness-greenness, and $b^{*}$ approximates yellowness-blueness as seen in the Figure 1, color coordinates are measured with a spectrophotometer (Equation 1) [14].

Discoloration of additive free PE is rarely significant and environmental conditions have little effect. Any slight discoloration that does occur is usually assigned to the formation of oxygen containing chromophoric groups [15]. However, significant color can develop in the presence of phenolic AOs. Sterically hindered phenols usually contribute to the discoloration (yellowing) of polymers as a result of melt processing and during service life. Color development in polyolefin formulations is widely thought to be due to transformation products of hindered phenolic AO that include highly chromophoric quinoidal structures. Thus, consequently we must assume that discoloration is proportional to the amount of stabilizer which reacts during processing of the polymer [16,17]. Stilbenequinone species are reported to be the major contributor to phenolic AO derived color formation in polymers $[18,19]$.

\section{Results and discussion}

Figure 2 shows a characteristic synergy curve for two different antioxidants. Note the average trend line was determined using the proportionally summed contributions of the single additives [6] and trend line for the real blend was obtained from the actual processed samples containing the AO blend. Note the represents the MFR of the highly stabilized benchmark control sample containing 5000 ppm of L-22IB46.

The synergism between two single additives can be understood in two different ways:

(a) Comparing the average (theoretical additive effect) with the actual effect of the real blend: if the real blend shows higher values in MFR than the average, there is synergy. 
(b) Comparing the real blend with the single additives; synergy is indicated if the data points for the real blend indicate superior performance relative to those on an imaginary line drawn between the data points at the $100 \%$ limits on the left and right hand y-axes.

\section{Melt processing stability and color development in blends of HDPE}

During initial scouting studies the total stabilizer loading was $1000 \mathrm{ppm}$, however this was quickly reduced to $500 \mathrm{ppm}$, as the higher loading was too comfortably within the limiting region of the MFR versus stabilizer level response curve. The following blends were assessed in this study:

During initial scouting studies the total stabilizer loading was $1000 \mathrm{ppm}$, however this was quickly reduced to $500 \mathrm{ppm}$, as the plateau was reached within the limiting region of the MFR versus stabilizer level response curve. The following blends were assessed in this study:

$\underline{\text { Total level } 1000 \mathrm{ppm}}$

Naugard $431(\mathrm{~N}-431)+$ Genox EP (G-EP): hindered phenolic AO + hydroxylamine

\% Ratios (N-431/G-EP) explored: 100:0, 80:20, 60:40, 40:60, 20:80, 0:100

\section{Total level $500 \mathrm{ppm}$}

Lowinox CPL (L-CPL) + Tinuvin 123 (T-123): moderately hindered phenolic AO + hindered amine light stabilizer.

Anox PP18 (A-PP18) + Alkanox TNPP (A-TNPP): hindered phenolic AO + phosphite.

Lowinox CPL (L-CPL) + Ultranox 626 (U-626): moderately hindered phenolic AO + high performance phosphate.

Genox EP (G-EP) + Ultranox 626 (U-626): hydroxylamine + high performance phosphite.

The same $\%$ ratios as above were examined. 


\section{Phenolic AO (with moderate steric hindrance of the phenolic $\mathrm{OH}$ ) combined with hindered amine light stabilizer}

This blend consists of L-CPL, which is one of the best phenolic AO for protection of PE during melt processing, and a hindered amine light stabilizer (T-123). HALS are generally added to improved melt stability and UV light. Phenolic AO, act as scavengers of oxygen-centred alkoxy and peroxy radicals.

Trends shown in Figure 3 indicate that there is no synergism between the phenolic AO (L-CPL) and HALS (T-123), only an additive effect can be observed. Strong competition between phenolic AO/ROO•, phenolic $\mathrm{AO} />\mathrm{NO} \bullet$ and $>\mathrm{NOH} / \mathrm{ROO} \bullet$ should be considered a factor affecting chain breaking [20,21]. HALS are excellent light stabilizers but also show heat stabilization activity below $120^{\circ} \mathrm{C}$. Therefore, HALS has to be combined with phenols and phosphites to give good protection to polyolefins in the melt. The combination phenolic AO / HALS also has a strong beneficial effect in thermal aging of polyolefins. However, the concentrations of the phenolic AOs and the HALS have to be selected carefully. A combination having a low level of phenolic AO and relatively high concentration HALS give the best results, as compared to samples without HALS [22].

The antagonism between HALS and phenolic AO was observed in all the ratios studied, and is clearly evident from the trends displayed in Figure 4 and Figure 5. Such antagonism has also been observed by other researchers $[23,24]$, and has been attributed to the formation of strongly chromophoric species. When used in isolation T-123 gives rise to less coloration than L-CPL; it can therefore be concluded that the transformation products of L-CPL are chromophoric. The difference is especially obvious after the fifth extruder passes: 500 ppm T-123 hardly shows any color increase from pass 1 to pass 5 .

The same antagonistic effect is confirmed in internal reports generated by Chemtura where different sterically hindered phenolic AOs were mixed with L-94 (HALS). The results show that the blend A-20 (hindered phenolic AO) / L-94, IC-14 (hindered phenolic AO) / L-94 do show synergy and L-1790 (Moderately hindered phenolic AO) / L-94 show an antagonistic effect in terms of color.

- Hindered phenolic AO + HALS= Synergy

- Moderately hindered phenolic AO + HALS= Antagonism 
Oxidation of phenols produces chromophoric products via what is considered to be mainly a free radical mechanism. Formation of phenoxy radicals from less hindered phenolic AOs requires lower activation energy relative to formation of such radicals from phenols featuring an $\mathrm{OH}$ group which has a greater level of steric hindrance. Phenolic AOs featuring $\mathrm{OH}$ groups that are less sterically hindered (termed in this paper as moderately hindered phenolic AOs), will react comparatively faster with $>\mathrm{NO} \bullet$ than $\mathrm{R} \bullet$ or ROO• as shown in the Scheme 1.

The HALS and phenolic AO are known to show synergism [20, 21] as well as antagonism [4,23,25]. The reaction mechanism is shown below for antagonism and synergism between HALS and phenols AO [24].

Sometimes synergy can occur as can be seen in the Scheme 2:

These results show a number of general features: (a) During thermal-oxidation, addition of hindered phenolic AO was found to antagonize the color stabilizing action of HALS over a wide range of concentration ratios, and (b) The thermal stabilizing efficiency of hindered piperidine compounds is dependent on the recycling of nitroxylradicals $(>\mathrm{NO} \bullet)$. The ability of the phenolic AO to prevent the formation of hydroperoxides during processing, which are important for the conversion of the parent amine to nitroxyl radical, will also contribute to the overall degree of antagonism [22].

\section{Hindered phenolic AO combined with organo-phosphite}

The use of phenolic and phosphite AO in combination with an acid scavenger is commonly encountered in PE stabilization. TNPP is a phosphite which, when used in isolation, can only partially protect against degradation of the polymer. A-PP18 is a highly hindered phenol AO with strong stabilization activity. The combination of the two products results a synergistic effect, especially at higher concentrations of A-PP18; a useful recommendable ratio could be $3: 2$ or 4:1 A-PP18/TNPP as shown in Figure 6.

For polyolefins, the melt stabilization synergism of phenolic AO / phosphite combinations is well known and is attributed to the complementary reaction mechanism associated with the strong radical scavenging ability of hindered phenolic AO and the peroxide decomposing activity of the phosphites. It is significant to note that such synergy occurs only at temperatures consistent with homolytic decomposition of hydroperoxides - after all the phosphite needs something with which to react. Therefore at low 
temperatures (below $80^{\circ} \mathrm{C}$ ), phosphites have no effect on the AO efficiency of phenols. Furthermore, when combined with phenolic $\mathrm{AO}$ at high temperatures, the most crucial role played by phosphites is hydroperoxide decomposition, rather than chain-breaking activity. However, the hindered aryl phosphites are better synergists than alkyl phosphites, indicating that their chain-breaking ability also makes a significant contribution. [26-28]. The synergistic stabilization action of phenolic and phosphite AO is summarized in the Scheme 3.

With reference to color development, Figure 7, the combinations of A-PP18 with A-TNPP showed almost the same results as a single additive and hardly added color to the polymer when processing. After the fifth pass the yellowness index still has values below zero so no color can be observed in the polymer. The single additives, the blend and the theoretical average show almost the same results, no changes can be observed so no synergy can be seen.

\section{Moderately hindered polymeric phenolic AO + high performance phosphite}

Mixtures of U-626 (a high performance phosphite) and the moderately hindered polymeric phenolic AO, L- CPL, did not show synergism in terms of melt stabilization (Figure 8).

It is important to appreciate the well-established mechanism of phosphite decomposition when the latter are combined with phenolic AOs [29]. Phosphite decomposition in these circumstances dramatically reduces the consumption of phenolic AO during melt stabilization (Scheme 4).

This sacrificial mechanism is verified in Figure 9. The use of $200 \mathrm{ppm}$ of U-626 (in combination with 300 ppm of L-CPL) leads to only a minor improvement in color stability after the first extruder pass. In fact comparatively over the same concentration range studied there is only a minor differential between the average and real effects of the additives here. It should also be noted that significant color stabilization is also observed when U-626 is used in isolation. This observation is in good agreement with the literature [30].

The effect of L-CPL on the discoloration of the polymer is more apparent after the fifth extruder pass. Figure 10 clearly shows that almost all of the phosphite has been consumed after the first extruder pass and cannot reduce the consumption of the phenolic $\mathrm{AO}$ as found on analysis after the $1^{\text {st }}$ extruder pass. 
After the fifth pass yellowing is not mediated by the addition of U-626 (the same results were observed for the blend of N-431/L-CPL). Data for the blend and L-CPL alone follow the sensibly the same trend, therefore, the phosphite itself does not actively increase the level of color formation. However, comparison of behavior with that predicted on the basis of a purely additive effect reveals antagonism at all the ratios.

\section{Hindered phenolic AO combined with a hydroxylamine}

A hydroxylamine, which functions via several stabilization mechanisms [3] to give both processing and long-term thermal ageing stability, is combined with a hindered phenolic AO. The particular hydroxylamine investigated G-EP, has a high molecular weight and is claimed to offer outstanding compatibility with the polymer.

Hydroxylamines can be effective AOs which provide good color and melt stabilization, even at low dosages. Hydroxylamines are multifunctional, they can act as carbon-centered radical scavenging CB-A as well as hydroperoxide decomposers as illustrated in Scheme 5 and 6.

Hydroxylamines can be used, in isolation or in combination with a primary or secondary antioxidant. Hydroxylamines act as a radical trap and so prevent thermal oxidation from the outset, and hence eliminate generation of alkoxy or hydroperoxide species. Primary or secondary antioxidants do not function as a radical trap, therefore combinations of hydroxylamines with primary or secondary AO are effective at interrupting the oxidation cycle at each degradation step [3].

The data displayed in Figure 11 shows that synergism is generally observed in PE containing hydroxylamine/phenolic AO combinations after melt processing. It can be seen that optimum synergism occurs at a 3:2 ratio of G-EP/N-431.

In terms of color stabilization, clear synergy can be seen after the fifth extruder pass (Figure 12), though after the first pass synergism is not as significant. The best ratio of G-EP/ N-431 for melt stabilization appears to be 3:2. In this case, G-EP shows the best results in terms of color suppression. This is not surprising considering that $\mathrm{N}-431$ is a hindered phenol and G-EP is a hydroxylamine. It is apparent that N-431 imparts color to the polymer. When mixed with G-EP, it is apparent that the extent of yellowing decreases. Genox EP generates hydroxylamine during melt processing and this acts as primary AO (via 
radical trapping) and as a secondary AO (via peroxide decomposition). It is the latter effect (in which hydroxylamine is reduced to a nitrone) that gives rise to very strong synergism, in terms of color stabilization during melt processing, when combined with phenolic AO. It is not certain whether this is due to the competitive reaction of $\mathrm{O}_{2}$ with $\mathrm{ROOH}$, direct reduction of quinones, or a combination of all three. Even though HALS forms nitrones during stabilization, they cannot act as a hydroperoxide decomposer, in the in the same manner as G-EP or hydroxylamines, because they are missing an $\alpha-\mathrm{CH}$. Even though, when used in isolation, T-123 is a more effective radical scavenger than G-EP in isolation (Figures 2 and 10, respectively). This is because steric hindrance around the nitrogen of T-123 improves the stability of the resulting radical.

\section{High performance phosphite combined with hydroxylamine}

In this case, the additives G-EP and U-626 were analyzed as it can be observed in Figure 13 and Figure 14. G-EP and U-626 show the same results in terms of color stabilization performance, and individually they add little color to the polymer when processing. After the fifth pass the yellowness index is still below zero and the polymer is not visibly colored. Data for the single additives, the actual blend and the theoretical average is sensibly coincident, therefore no synergy was observed. These observations were not unexpected because G-EP and U-626 are the best of their types in terms of color protection. No synergy can be observed in this blend in terms of color and melt stability, the values for the single additives and the values for the blend are the same.

\section{Melt processing stability and color development in blends of m-LLDPE and ZN-LLDPE}

The same studies were carried out using two other PEs, produced via different catalyst technologies; Metallocene LLDPE (m-LLDPE) and Ziegler-Natta LLDPE (ZN-LLDPE).

The selected additive blends are the following:

Total level 500 ppm (100-200-300-400-500 ppm)

Lowinox CPL + Genox EP: moderately hindered polymeric phenolic AO + hydroxylamine Anox PP18 + Alkanox TNPP: hindered phenolic AO + phosphites.

Lowinox CPL + Ultranox 626: moderately hindered polymeric phenolic $\mathrm{AO}+$ high performance phosphate. 
The same basic trends as previously described for the AO blends in Phillips HDPE were obtained for the above AO blends in the m-LLDPE and ZN-LLDPE. The only noticeable exception was in the MFR data for m-LLDPE stabilized with a blend A-PP18 and A-TNPP; in this particular case synergy between these stabilizers was absent. Therefore this study, performed with the stabilizer combinations and PE samples described, indicates that polymerization catalyst type has no influence on stabilizer interactions.

\section{Conclusions}

Blends of primary AO, secondary AO and HALS have studied with the intention of further improving stabilization performance together with cost reduction of the stabilized polymer. Although synergism between antioxidants and other stabilizer types is fairly common, antagonism was also observed in terms of melt flow protection and in color stability in some of the AO combinations examined.

The well-established suppression of chromophore development via combination of moderately hindered phenolic AOs with phosphites was confirmed. However, the stabilizer activities and synergism of blends were found to be independent of the catalyst system used to prepare the polyethylene. The latter in itself is an interesting observation which is likely to impact on stabilization strategies for polyethylene. Indeed catalyst residues such as $\mathrm{Zr}$ and $\mathrm{Cr}$ have been shown in previous studies to impact on the degradation and oxidation behavior of different polyethylene types i.e. chain scission versus crosslinking and in particular color formation [32]. But, in fact, it would appear that once stabilization packages are incorporated such behavioral characteristics become unimportant perhaps associated with the multi-fun

\section{References}

[1] P. P. Klemchuk, P. Hong, Polym. Degrad. Stab., 7, 131 (1984).

[2] A. J. Chirinos-Padron, P. H. Hernández., Polym. Degrad. Stab., 9, 177 (1987).

[3] J. Murphy, Additives for Plastics Handbook, London (2003).

[4] H. Yamashita and Y. Ohkatsu, Polym. Degrad. Stab., 80, 1421 (2003).

[5] P. Jan, Polym. Degrad. Stab., 34, 1(1991).

[6] K. del Teso Sanchez, N.S Allen, C.M Liauw, B. Johnson, J. Vinyl and Additive Technol., 17, 28 (2011). 
[7] K. del Teso Sanchez, N. S. Allen, C. M Liauw, B. Johnson, M. Edge, J. Vinyl and Additive Technol., 18, 26 (2012).

[8] A. Parrondo, N. S. Allen, M. Edge, C. M. Liauw, E. Fontán, T. Corrales, J. Vinyl and Additive Technol., 8, 75 (2002).

[9] E.M Hoang, C. M. Liauw, N. S. Allen, E. Fontán, P. Lafuente, J. Vinyl and Additive Technol., 10, 149 (2004).

[10] British Resin Products, Rigidex High Density Polyethylene, London (1964).

[11] E.M Hoang, N. S. Allen, C. M. Liauw, E. Fontán, P. Lafuente, Polym. Degrad. Stab., 91, 1363 (2006).

[12] S. Yachigo, K. Ida, M. Sasaki, K. Inoue, S. Tanak, Polym. Degrad. Stab., 39, 317 (1993).

[13] J. Posposil, S. Nespurek, H. Zweifel, Polym. Degrad. Stab., 54, 7 (1996).

[14] M.D. Fairchild, Color Appearance Models. 3rd Ed. Wiley-IS\&T, Chichester, UK (2013).

[15] A. Holmstrom, E. M. Sorvik,. J. Applied Polym. Science, 18, 761 (1974).

[16] E. Epacher, J. Tolveth, K. Stoll, B. Pukansky, J. Applied Polym. Science 74, 1596 (1999).

[17] E. Epacher, E. Fekete, M. Gahleitner, B. Pukanszky, Polym. Degrad. Stab., 63, 489 (1999).

[18] O. D. Bangee, V. H. Wilson, G. C. East, I. Holme, Polym. Degrad. Stab., 50, 313 (1995).

[19] P.P. Klemchuk, P. Hong. Polym. Degrad. Stab., 34, 1(1991).

[20] P. Jan, Polym. Degrad. Stab., 39, 103 (1993).

[21] J. Posposil, S. Nespurek, Polym. Degrad. Stab., 49, 99 (1995).

[22] J. Pospisil, S. Nespurek, H. Zweifel, Polym. Degrad. Stab., 54, 15 (1996).

[23] N. S Allen, C. Vasiliou, G.P. Marchall, W.Chen, Polym. Degrad. Stab., 24, 17 (1989).

[24] H. Yamashita, Y. Ohkatsu, Polym. Degrad. Stab., 80, 421 (2003).

[25] I. Bauer, W.D. Habicher, S. Korner, S. Al-Malaika, Polym. Degrad. Stab., 55, 217 (1997).

[26] K. Sohwetlick, Pure and Applied Chemistry, 55, 1629 (1983).

[27] I. Bauer, S. Körner, B. Pawelke, S. Al-Malaikab, W.D. Habicher, Polym. Degrad. Stab., 62, 175 (1998).

[28] H. Zweifel, Plastics Additive Handbook. Munich, Hanser (2009).

[29] S. Moss, H. Zweifel, Polym. Degrad. Stab., 25, 217 (1989).

[30] S. Al-Malaika, S. Issenhuth, Polym. Degrad. Stab., 65, 143 (1999).

[31] W. Voight R. Todesco, Polym. Degrad. Stab., 77, 397 (2002).

[32] N.S Allen, C.M Liauw, A.Reyes, M. Edge, B. Johnson, K. Neck-Antoine. J. Vinyl and Additive Technol., 15, 12 (2009). 
Table 1. Properties of polyethylene types investigated.

\begin{tabular}{|l|c|c|c|}
\hline Polymer & Phillips HDPE & Metallocene LLDPE & Zeigler-Natta LLDPE \\
\hline Coding & Ph-HDPE & m-LLDPE & ZN-LLDPE \\
\hline $\begin{array}{l}\text { Metallic catalyst } \\
\text { residue }\end{array}$ & $\mathrm{Cr}$ & $\mathrm{Zr}$ & $\mathrm{Ti}$ \\
\hline MFR $\left(190^{\circ} \mathrm{C} / 21.6 \mathrm{~kg}\right)$ & 29.38 & 14.80 & 24.75 \\
\hline MFR $\left(190^{\circ} \mathrm{C} / 10 \mathrm{~kg}\right)$ & 5.82 & 5.37 & 7.22 \\
\hline Application & $\begin{array}{c}\text { Blow moulded } \\
\text { containers }\end{array}$ & Film & Film \\
\hline
\end{tabular}


Table 2. Hindered phenolic antioxidants investigated

$\begin{aligned} & \text { Trade name } \\ & \text { (abbreviation in } \\ & \text { parenthesis) }\end{aligned}$
$\begin{aligned} & \text { Structure } \\ & \begin{array}{l}\text { Anox PP18 } \\ \text { (Ange }\end{array}\end{aligned}$


Table 3. Phosphite and thioether stabilizers investigated

\begin{tabular}{|c|c|c|c|c|}
\hline $\begin{array}{l}\text { Trade name } \\
\text { (abbreviation in } \\
\text { parenthesis) }\end{array}$ & Structure & $\begin{array}{l}\text { Melting } \\
\text { range } \\
\left({ }^{\circ} \mathrm{C}\right)\end{array}$ & $\begin{array}{l}\text { Molar } \\
\text { mass } \\
(\mathrm{gr} / \mathrm{mol})\end{array}$ & $\begin{array}{l}\text { Molar } \\
\text { Activity } \\
\text { (mol P / } \\
\text { kg AO) }\end{array}$ \\
\hline
\end{tabular}

Ultranox 626
(U-626)
Alkanox TNPP


Table 4. Amine hydroxylamine and HALS stabilizers investigated.

\begin{tabular}{lllll}
\hline $\begin{array}{l}\text { Trade name } \\
\text { (abbreviation in } \\
\text { parenthesis) }\end{array}$ & Structure & $\begin{array}{l}\text { Melting } \\
\text { range }\left({ }^{\circ} \mathrm{C}\right)\end{array}$ & $\begin{array}{l}\text { Molar } \\
\text { mass } \\
(\mathrm{gr} / \mathrm{mol})\end{array}$ & $\begin{array}{l}\text { Molar Activity } \\
(\mathrm{mol} \mathrm{N} / \mathrm{kg} \mathrm{AO})\end{array}$ \\
\hline $\begin{array}{l}\text { Genox EP } \\
(\mathrm{G}-\mathrm{EP})\end{array}$ &
\end{tabular}

*Per repeat unit 
Table 5. Temperature profile of the extruder.

\begin{tabular}{llll}
\hline Passes & \multicolumn{3}{l}{ Set zone temperatures $\left({ }^{\circ} \mathrm{C}\right)$} \\
\hline 0 (under $\left.\mathrm{N}_{2}\right)$ & Hopper & $175 / 175 / 180 / 190$ & Die \\
$1,2,3,4$ and 5 (in air) & Hopper & $200 / 210 / 220 / 230$ & Die \\
\hline
\end{tabular}




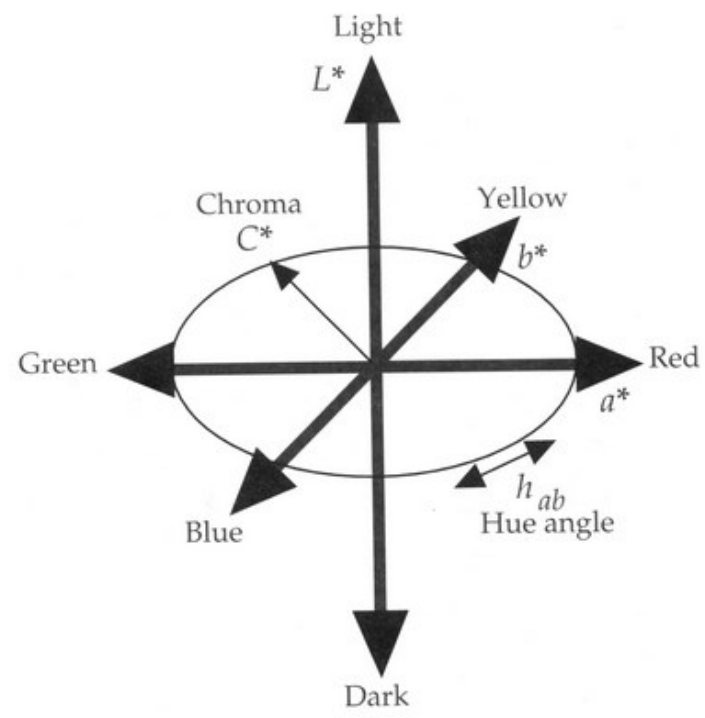

Figure 1. Three dimensional model of color measurement 


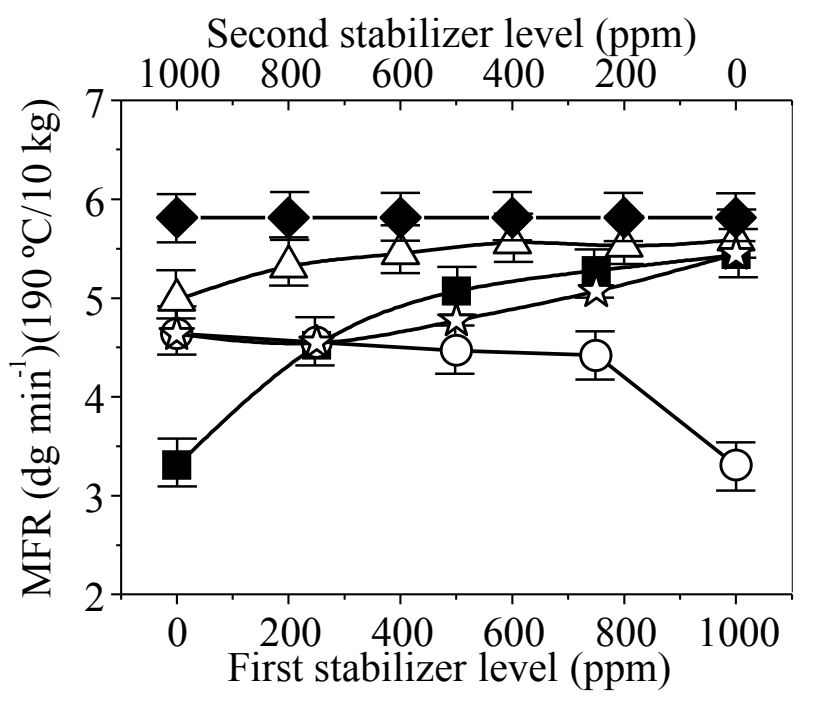

Figure 2. MFR versus stabilizers level: $\boldsymbol{a}$ first stabilizer level, o second stabilizer level, $\triangle$ real blend, $\vec{t}$ average, $\diamond$ benchmark. 


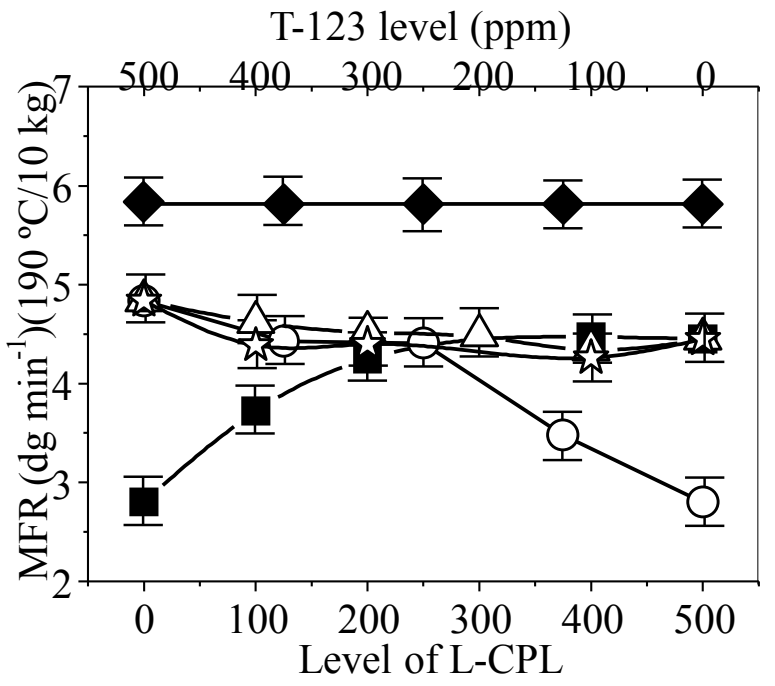

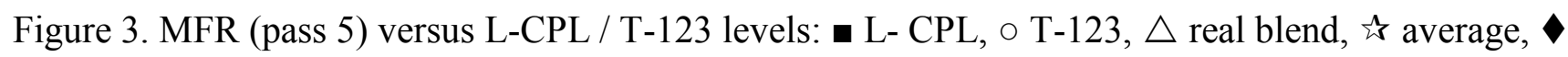
benchmark. 


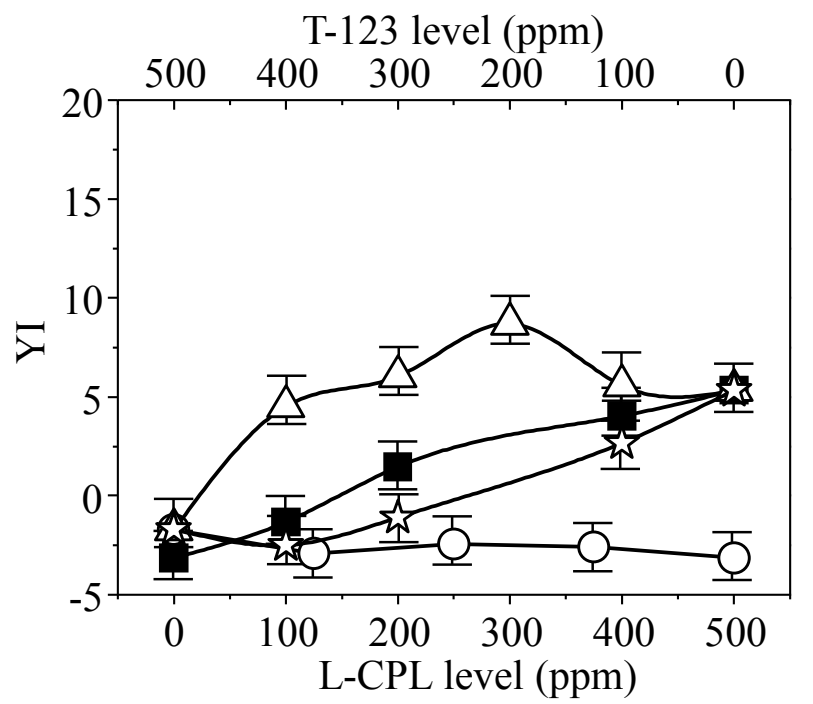

Figure 4. Yellowness index (YI) (pass 1) versus L-CPL / T-123 level: $\mathbf{\square}$ L-CPL, ○ T-123, $\triangle$ real blend and $\hat{z}$ average. Strong antagonism is apparent. 


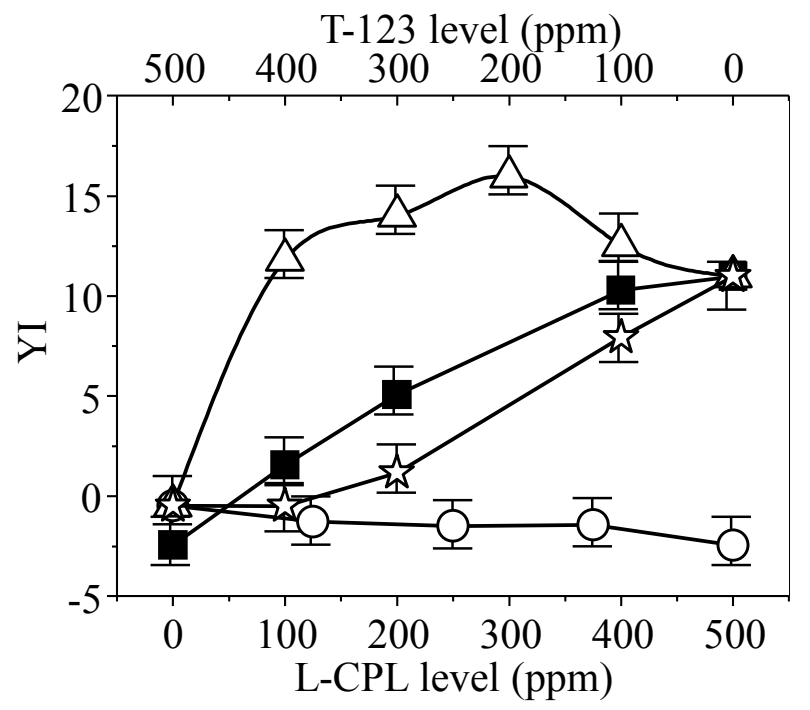

Figure 5. Yellowness index (YI) (pass 5) versus L-CPL / T-123 level: $\mathbf{\text { a }}-\mathrm{CPL}, \circ \mathrm{T}-123, \triangle$ real blend and $\hbar$ average. Even stronger antagonism is apparent. 


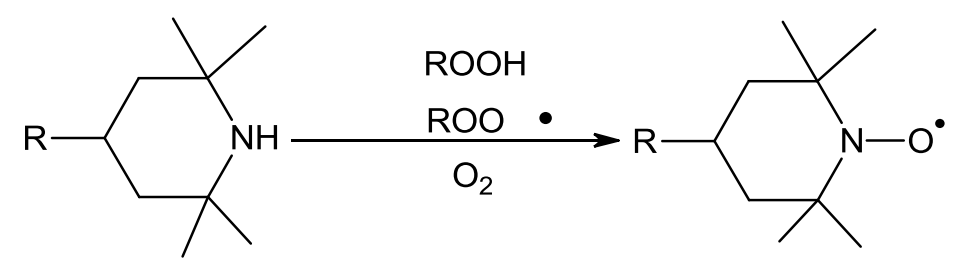

Hindered amine light stabiliser $\quad$ Nitroxyl radical (coloured species)<smiles>[R]C1CC(C)(C)N([O])C(C)(C)C1</smiles>

Nitroxyl radical<smiles>[R]c1cc([R2])c(O)c([R])c1</smiles>

Phenolic AO

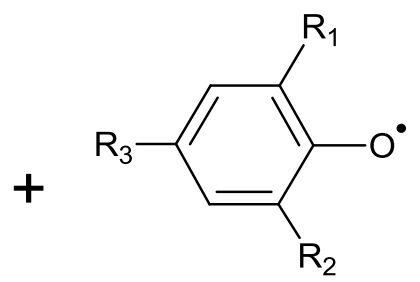

Coloured species$$
\text { (1) }
$$<smiles>[R]C1CC(C)(C)N([O])C(C)(C)C1</smiles>

Nitroxyl radical<smiles>[R3]c1cc([R])c(O)c([R])c1</smiles>

Phenoxyl radical<smiles>[R]C1CC(C)(C)N(O)C(C)(C)C1</smiles><smiles>[R]C1=CC([R3])(ON2C(C)(C)CC([R])CC2(C)C)C=C([R])C1=O</smiles>

Coloured species

Scheme 1. Antagonism between HALS and phenolic AOs. [4,23] 
del Teso et al

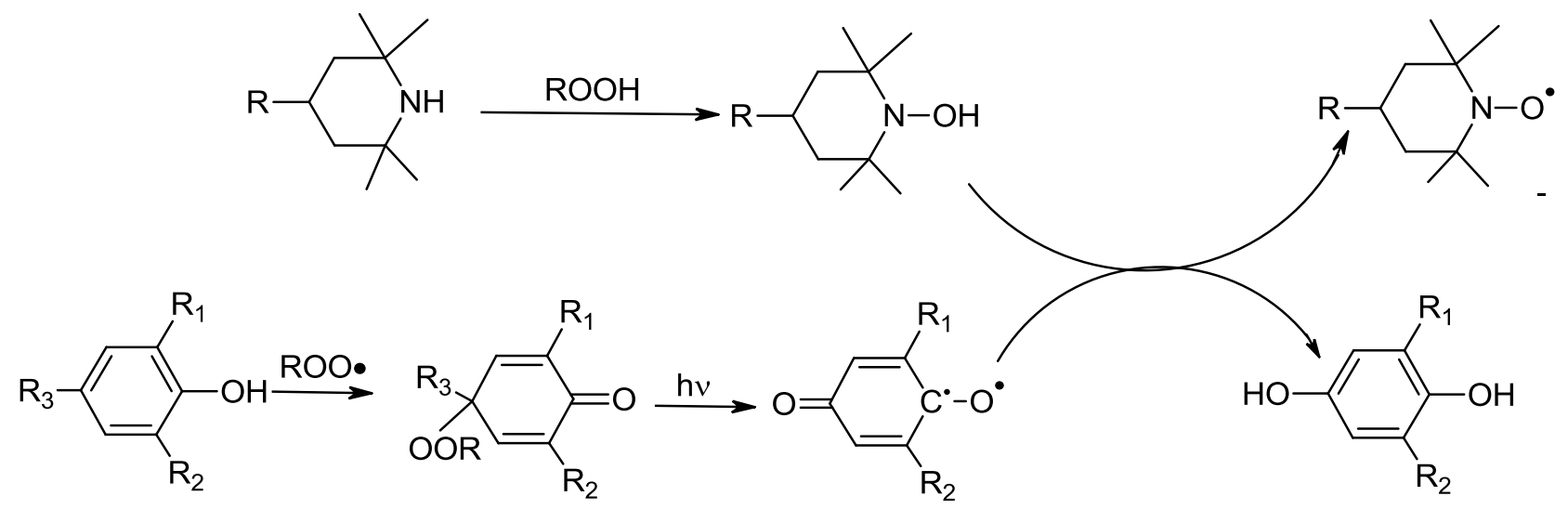

Scheme 2. Synergisms between HALS and phenolic AOs. [20,21] 
del Teso et al

Figure 6

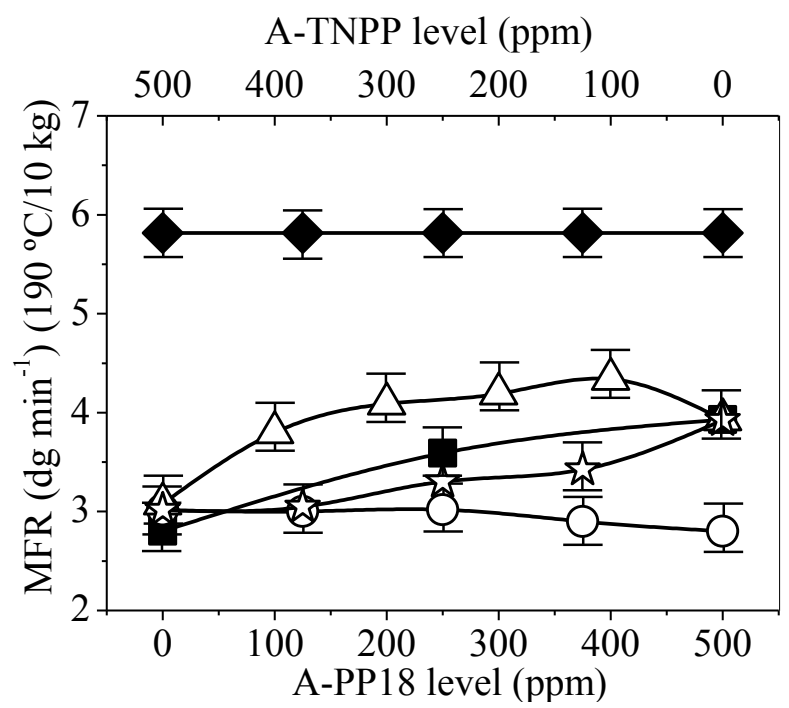

Figure 6. MFR (pass $5\left(10 \mathrm{~kg}, 190^{\circ} \mathrm{C}\right)$ ) versus A-PP18 / A-TNPP level: - A-PP18, ○A-TNPP, $\triangle$ real blend, is average, benchmark. Moderate synergism is apparent. 


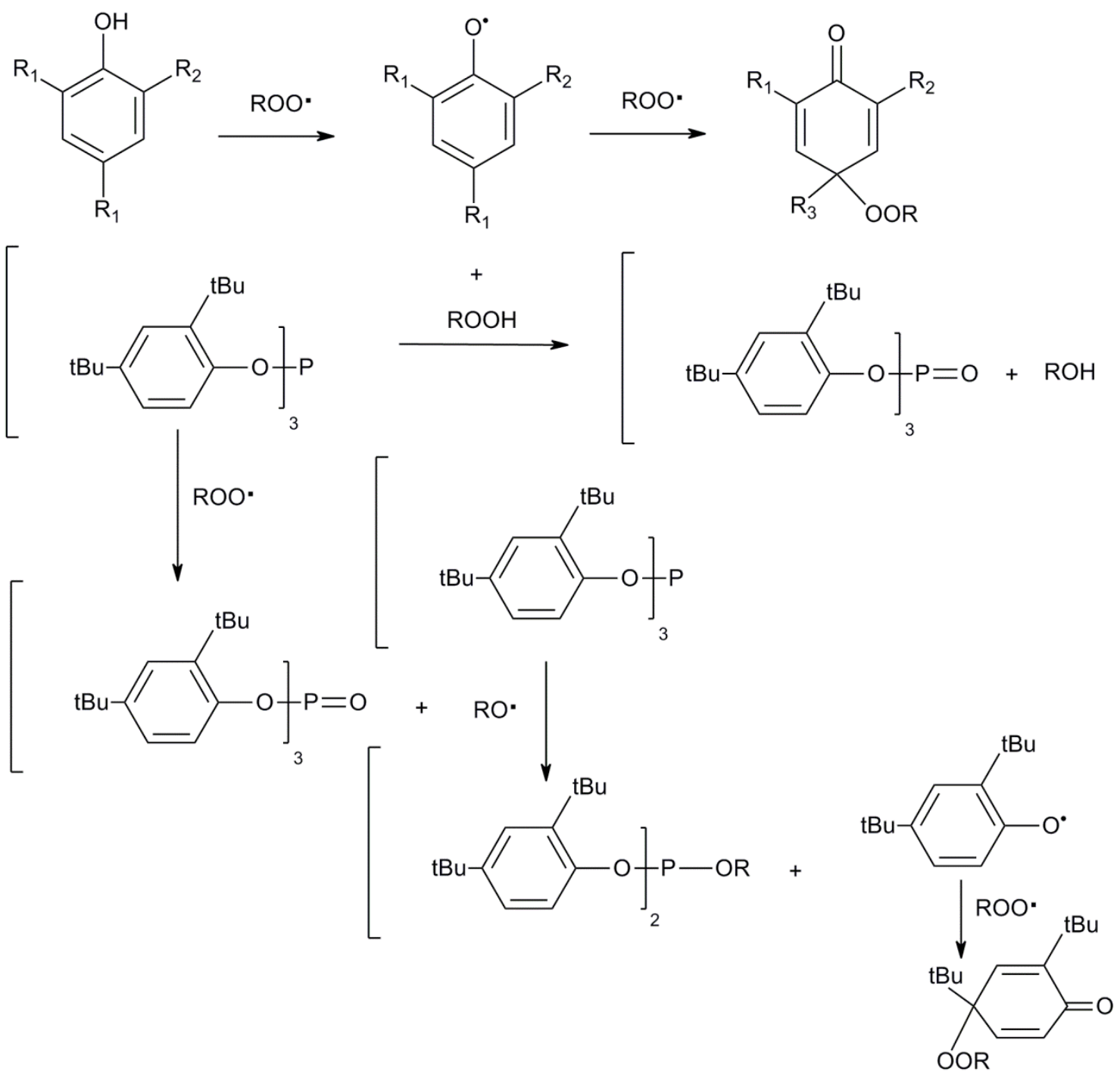

Scheme 3. Synergistic stabilization action of phenolic and phosphite AO. 


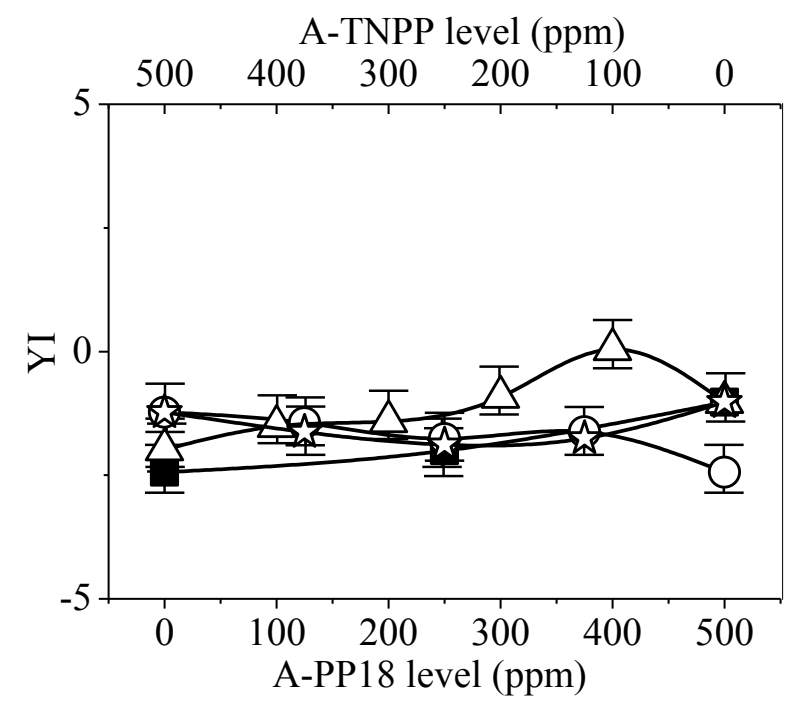

Figure 7. YI (pass 5) versus A-PP18 / A-TNPP level: a A-PP18, ○ A-TNPP, $\triangle$ real blend, is average. 


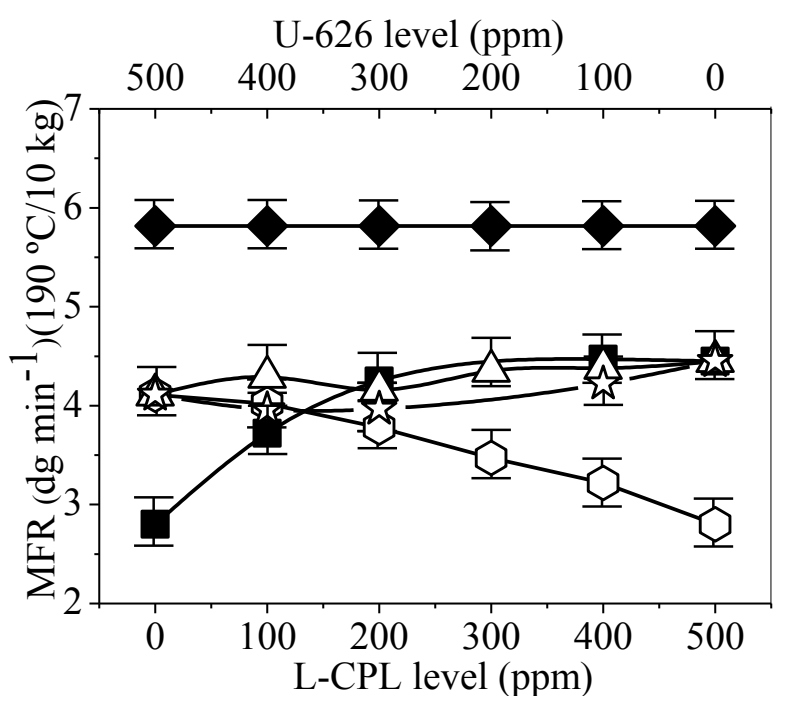

Figure 8. MFR (pass 5) versus L-CPL / U-626 level: $\mathbf{L}$ L-CPL, ○ U-626, $\triangle$ real blend, $\downarrow$ average, benchmark. 


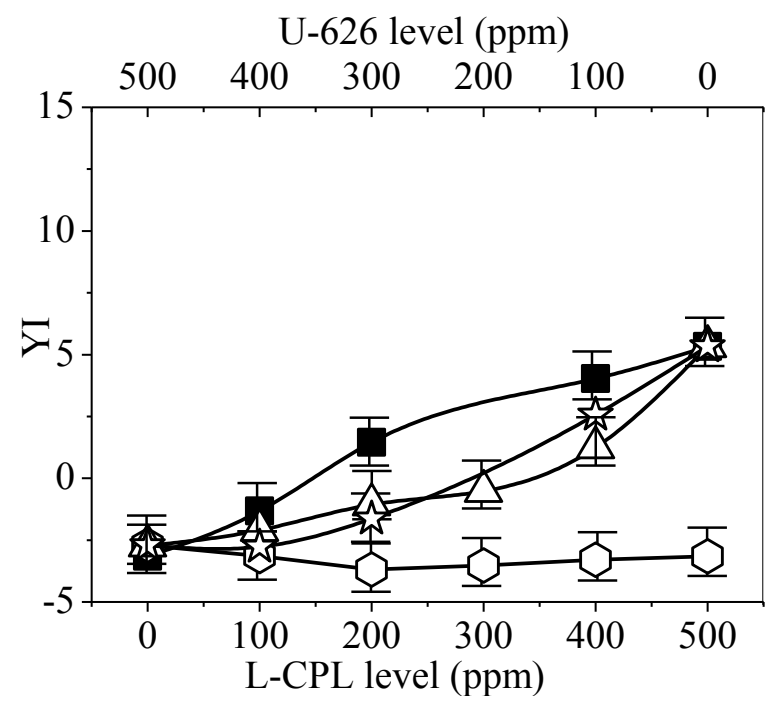

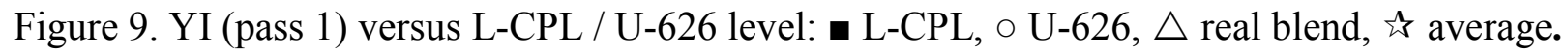




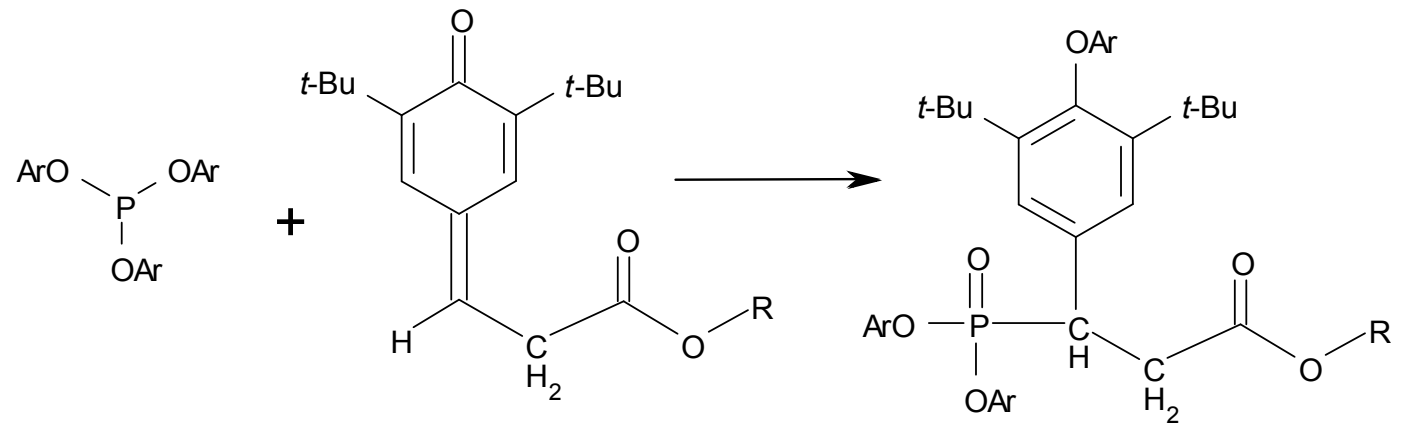

Phosphonate

QM (highly coloured)

Aryl phophonate (colourless)

Scheme 4. Reaction of phosphate AO with coloured quinone derivatives. 


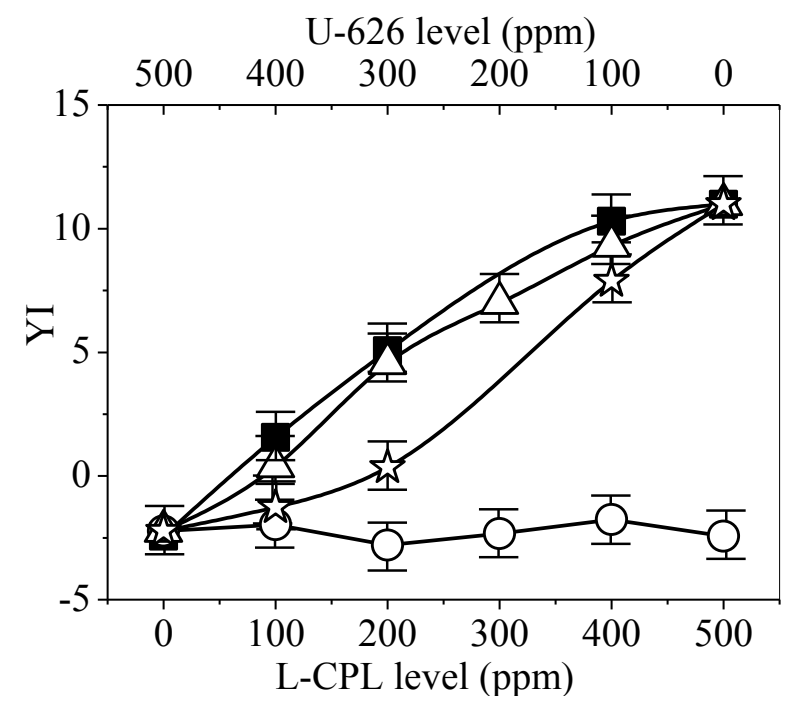

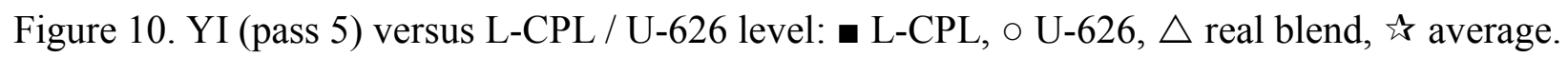




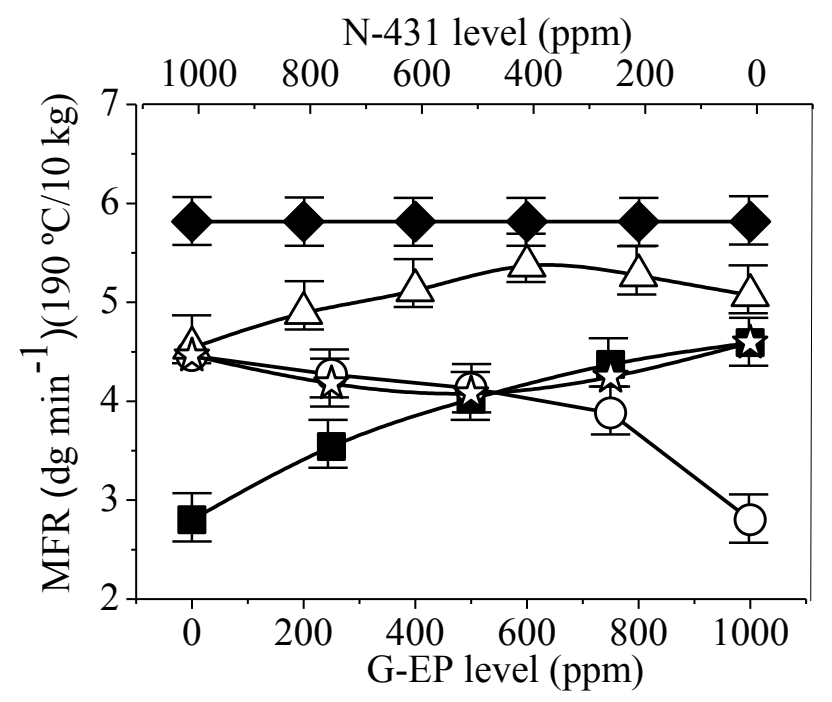

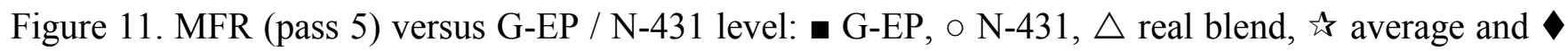
benchmark. 


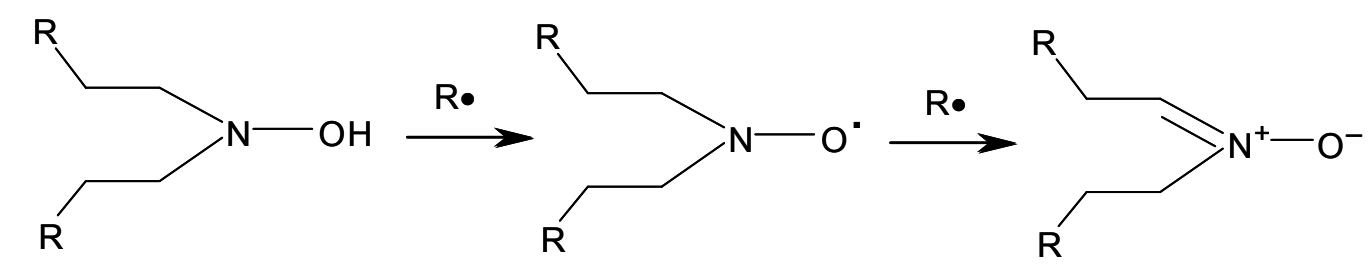

Scheme 5. Free radical decomposition mechanism for hydroxylamines. [31] 


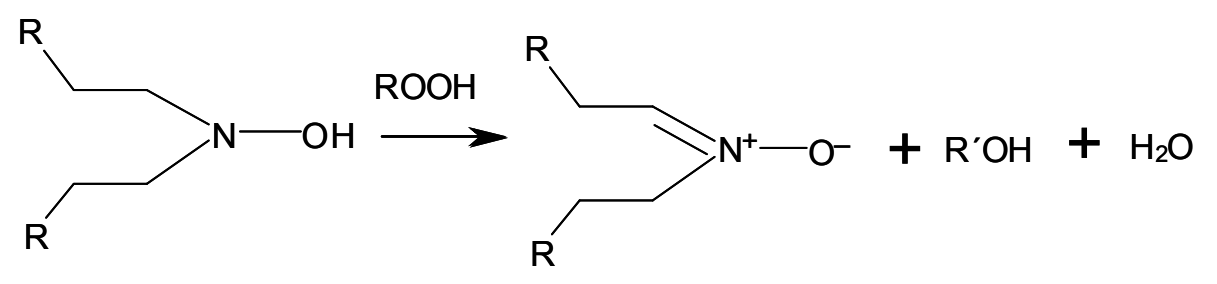

Scheme 6. Hydroperoxide decomposition mechanism for hydroxylamines. [31] 


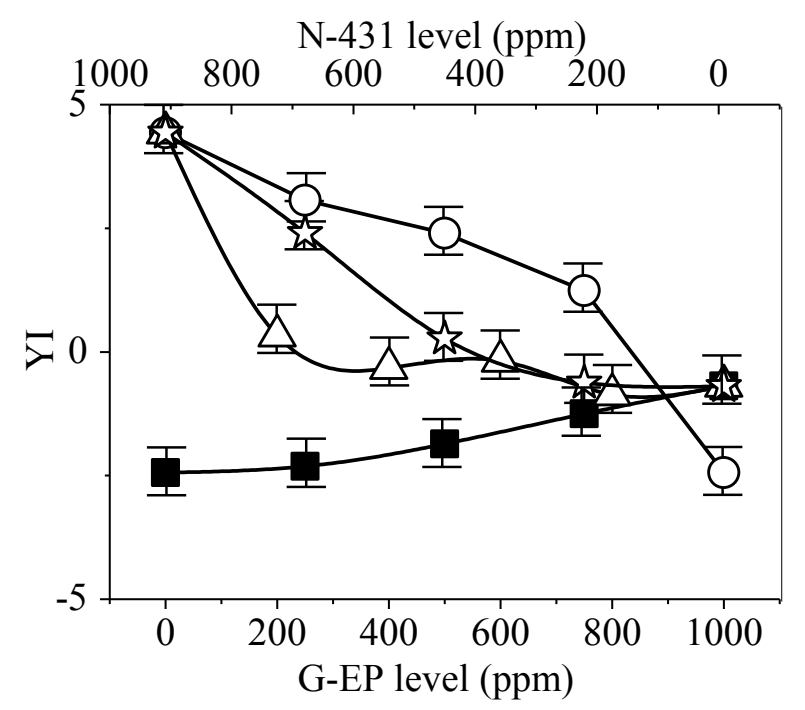

Figure 12. YI (pass 5) versus G-EP / N-431: — G-EP, $\circ$ N-431, $\triangle$ real blend, $\dot{*}$ average. 


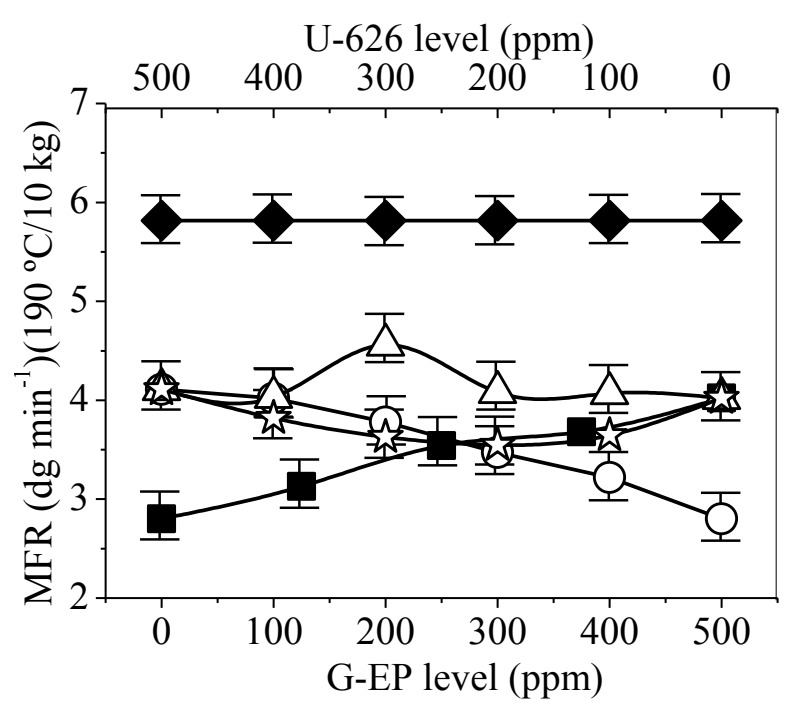

Figure 13. MFR (pass 5) versus G-EP / U-626 level:a G-EP, ○ U-626, $\triangle$ real blend, $\downarrow *$ average and $\bullet$ benchmark. 


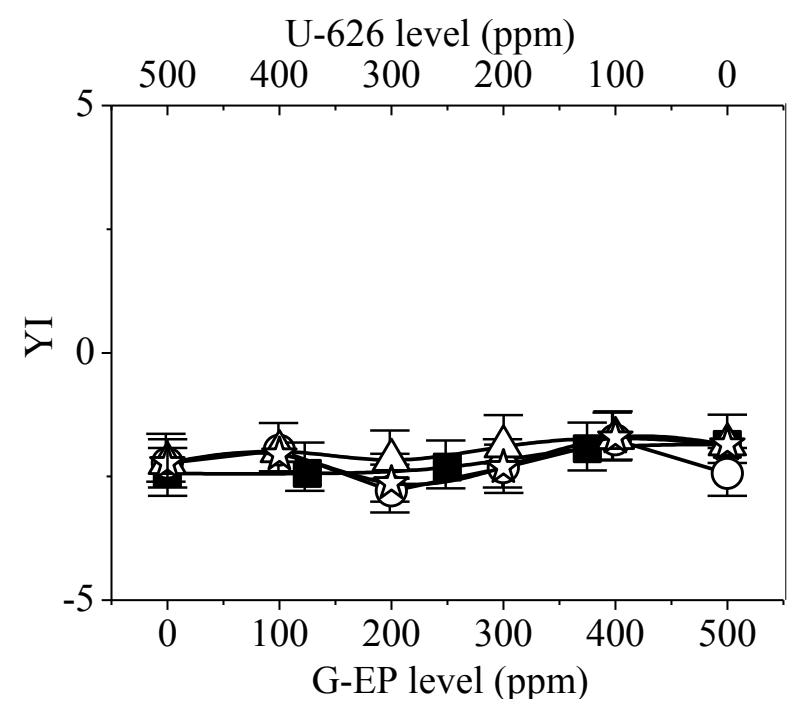

Figure 14. YI (pass 5) versus G-EP / U-626 level: a G-EP, ○ U-626, $\triangle$ real blend, is average. 